\title{
Mobilidade populacional, sustentabilidade ambiental e vulnerabilidade social ${ }^{*}$
}

\author{
Daniel Joseph Hogan ${ }^{*}$
}

\begin{abstract}
O artigo sintetiza pesquisa sobre população e ambiente, com ênfase no caso brasileiro. A atenção é dirigida especialmente às relações entre padrões de distribuição populacional no espaço e a mudança ambiental. Como taxas de mortalidade e fecundidade já passaram por transições enormes, migração é o fator central na mudança populacional e seus impactos sobre o ambiente. No longo prazo, essa é a variável que sempre inspirará preocupação. Embora a grande migração interna da segunda metade do século XX (campo-cidade e inter-regional) tenha diminuído consideravelmente, os fluxos intra-regionais continuam a ser importantes. Outros processos de mobilidade, especialmente a migração pendular e o turismo, também afetam a integridade de recursos naturais e terão de ser avaliados continuamente. O zoneamento ecológico-econômico, com seus impactos sobre a mobilidade populacional, será um requisito básico do século XXI.
\end{abstract}

Palavras-chave: Mobilidade populacional. Migração. Ambiente. Urbanização. Zoneamento ecológico-econômico.

\section{Introdução}

Em 1992, quando da realização da Conferência das Nações Unidas para Meio Ambiente e Desenvolvimento, a demografia como disciplina não tinha a importância que mais tarde assumiria para o estudo do ambiente. Um dos primeiros desafios para os demógrafos, quando identificaram um lugar no debate além da polêmica sobre as conseqüências do rápido crescimento populacional, foi confrontar a visão quase unânime dos ativistas e cientistas ambientais de que o problema era população demais e recursos de menos. Embora o tamanho da população e as taxas de crescimento não sejam assuntos irrelevantes, o enfoque exclusivo nestes temas deixou os especialistas em questões demográficas à margem do debate. Atribuir a crise ambiental a esse fator era simplificar as análises demográficas, especialmente considerando as tendências declinantes observadas desde os anos 70 .

Essas tendências tornam-se mais evidentes a cada censo de população. As taxas de crescimento populacional têm declinado em todos os países latino-americanos, freqüentemente a ritmos históricos sem precedentes. Taxas de crescimento por

\footnotetext{
* Este texto é uma versão revisada e atualizada de "Movilidad poblacional, sustentabilidad ambiental y vulnerabilidad social: una perspectiva latinoamericana", trabalho publicado em E. Leff, E. Ezcurra, I. Pisanty e P. Romero Lankao (comps.), La transición hacia el desarrollo sustentable. Perspectivas de América Latina y el Caribe, INE/Semarnat, Unam, Pnuma, México, 2002.

${ }^{* *}$ Professor do Departamento de Demografia e pesquisador do Núcleo de Estudos de População (Nepo) da Universidade Estadual de Campinas (Unicamp).
} 
períodos de cinco anos, de 1950 a 2050, estimadas pela Comissão Econômica para América Latina e o Caribe (Cepal), revelam o considerável declínio já observado e a redução esperada para a primeira metade do novo século (ver Quadro 1). Considerando o momentum do crescimento populacional, a fecundidade de reposição - esperada para 2025 - demorará para ser traduzida em crescimento zero. Por outro lado, vale notar que esses dados supõem que o declínio de fecundidade terminará quando chegar à taxa de 2,1 filhos por mulher, embora esta não tenha sido a experiência daqueles países que já alcançaram essas taxas. Como o declínio de fecundidade na América Latina pode ser semelhante àquele da Europa, é perfeitamente possível que o crescimento zero seja alcançado antes do que se espera.
O crescimento urbano também tem reduzido sua velocidade. Em três quartas partes dos 20 países latino-americanos as taxas de crescimento urbano alcançaram seu ponto máximo nos anos 50 e 60; em dois países (Bolívia e Nicarágua), nos anos 70, e em três (Paraguai, Haiti e Honduras) nos 80 . Em todos os países grandes houve um declínio especialmente marcado nas taxas de crescimento urbano entre os anos 70 e 80. As projeções das Nações Unidas para o período 1995-2005 confirmam essa tendência. Entre 1980 e 2005 as taxas de crescimento urbano terão declinado regularmente em todos os países menos a Bolívia, El Salvador, Guatemala e Nicarágua, onde pequenos movimentos ascendentes ainda são esperados. Esse declínio universal ainda não produziu um padrão homogêneo na região. Espera-se que as

QUADRO 1

América Latina: Taxas de crescimento totais estimadas e taxas de fecundidade totais estimadas, 1950-2050

\begin{tabular}{|c|c|c|c|}
\hline \multicolumn{2}{|c|}{ Qüinqüênio } & \multirow{2}{*}{$\begin{array}{c}\text { Taxa de Crescimento } \\
\text { Total } \\
27,0\end{array}$} & \multirow{2}{*}{$\begin{array}{c}\text { Taxa de Fecundidade } \\
\text { Total }\end{array}$} \\
\hline 1950 & -1955 & & \\
\hline 1955 & -1960 & 27,3 & 5,9 \\
\hline 1960 & -1965 & 27,8 & 6,0 \\
\hline 1965 & -1970 & 26,2 & 5,6 \\
\hline 1970 & -1975 & 24,9 & 5,1 \\
\hline 1975 & -1980 & 23,5 & 4,5 \\
\hline 1980 & - 1985 & 21,0 & 3,9 \\
\hline 1985 & - 1990 & 19,2 & 3,4 \\
\hline 1990 & - 1995 & 17,4 & 3,0 \\
\hline 1995 & -2000 & 16,0 & 2,7 \\
\hline 2000 & -2005 & 14,6 & 2,5 \\
\hline 2005 & -2010 & 13,2 & 2,4 \\
\hline 2010 & -2015 & 12,0 & 2,3 \\
\hline 2015 & -2020 & 10,7 & 2,2 \\
\hline 2020 & -2025 & 9,4 & 2,2 \\
\hline 2025 & -2030 & 8,4 & 2,1 \\
\hline 2030 & -2035 & 7,2 & 2,1 \\
\hline 2035 & -2040 & 6,2 & 2,1 \\
\hline 2040 & -2045 & 5,2 & 2,1 \\
\hline 2045 & -2050 & 4,3 & 2,1 \\
\hline
\end{tabular}

Fonte: Latin America and Caribbean: population estimates and projections. Demographic Bulletin, Economic Comission for Latin America and the Caribbean, n. 69, January 2002. 
taxas de crescimento para o período 20002005 variem de $0,9 \%$ ao ano no Uruguai a $4,2 \%$ ao ano em Honduras (Cunha, 2002).

O declínio das taxas de urbanização, por outro lado, foi acompanhado por mudanças importantes na estrutura familiar. Envelhecimento da população, redução do tamanho da família e novas formas de casamento têm levado a unidades domésticas multigeracionais menores e ao aumento do número de domicílios unipessoais. Entre os anos 80 e 90 o tamanho médio dos domicílios declinou em todos os países da região (Naciones Unidas, 2001, p. 148-149) e hoje flutua entre 5,1 pessoas por família em Honduras e 3,2 no Uruguai. A taxa de crescimento dos domicílios é hoje maior que a taxa de crescimento da população. A mudança nos padrões de consumo que isso representa terá importantes efeitos ambientais. As taxas declinantes de crescimento populacional não são nenhuma panacéia para a qualidade ambiental.

Essa desativação da bomba populacional, há muito esperada pelos demógrafos, levou a uma atitude de laissez-faire em relação aos problemas de população e ambiente. A disciplina demoraria muitos anos para perceber que sua contribuição poderia ir além daquela questão. Eventualmente, os impactos recíprocos entre os fatores ambientais e a saúde ou entre o uso de recursos e os processos de distribuição populacional seriam reconhecidos como questões importantes com conteúdo demográfico. Os esforços para lidar com esses temas nos anos 90 levaram os demógrafos a ampliar seu campo de ação sobre as relações população-ambiente.

Para os demógrafos, com sua afinidade com os grandes números em níveis gerais de análise, não foi fácil tratar variáveis ambientais. O progresso viria com estudos locais que permitem a identificação das condições ecológicas, que têm uma imensa variação de um lugar a outro. Exemplos de investigações localizadas que começam a surgir são a pesquisa de Provencio e Carabias (1993) em quatro zonas ecológicas do México rural; o planejamento de Pezzoli (1998) para a sustentabilidade ecológica da Cidade do México; o trabalho de Lutz, Prieto e Sanderson (2000) na península de Yucatán e uma série de estudos coordenados por Hogan no Brasil (Hogan, 1996; Hogan, Cunha e Carmo, 2001; Hogan et al., 2001). Estudos de bacias hidrográficas (Hogan, 1996; Ezcurra et al., 1999), por exemplo, têm reforçado a política de delimitar zonas econômico-ecológicas como um instrumento de planejamento fundamental. O zoneamento significa o reconhecimento de que a vocação socialmente determinada de algumas regiões é a de serem centros de agricultura e indústria modernas. Nestes casos, o dano ambiental deve ser controlado e minimizado, mas ninguém sugere que essas regiões sejam reflorestadas tal como eram há 200 anos. Áreas intactas, por outro lado, têm sido objeto de intensos esforços de preservação. A capacidade de carga de uma região específica, nessa perspectiva, depende da determinação social e política do lugar que ocupa no marco das metas maiores de uma sociedade.

\section{Distribuição populacional e ambiente: $\mathbf{P} \rightarrow \mathbf{A}$}

Vista, fundamentalmente, como uma causa de mudança ambiental, a migração começa a receber a atenção necessária (Hogan, 1993). Como apontam Zaba e Clarke (1994, p. 13),

a migração, em seu sentido mais amplo, inclui processos tais como a urbanização, o turismo e a migração pendular, os quais podem mudar radicalmente a relação entre população nativa ou residente e seu meio ambiente.

Apesar de sempre presente na discussão de processos de distribuição populacional, a questão dos recursos naturais apenas recentemente tornou-se o centro das atenções na investigação sobre regiões específicas (Hogan, 1998).

De maneira geral, existe considerável desacordo sobre a relevância da mudança ambiental para a migração. Alguns pesquisadores caracterizam as condições ambientais como simplesmente mais um dos push factors que influenciam as decisões de migrar. No presente artigo, defendo a idéia de que o estudo da relação 
entre mobilidade e ambiente não é simplesmente uma extensão dos estudos de migração, que incorporam mais uma dimensão, senão uma exigência de uma nova situação histórica na qual as relações entre homem e natureza são qualitativamente diferentes. O termo mobilidade é usado como um conceito mais amplo que migração, já que considera que uma parte crescente dos movimentos da população com impactos sociais, econômicos, políticos e ambientais não pode ser caracterizada como "mudanças de residência permanentes ou semipermanentes" (Lee, 1966), senão como movimentos circulatórios ou temporais de curta duração.

Não estão incluídos, por exemplo, os movimentos contínuos e aqueles dos trabaIhadores migrantes, para quem não há residência durante um período prolongado, assim como mudanças temporárias, como aqueles deslocamentos às montanhas durante as férias de verão. (Lee, 1966)

Isto é, Lee não incluía os movimentos que hoje assumem uma importância crescente. Na América Latina, os movimentos migratórios que ocuparam a atenção dos especialistas nas décadas recentes (movimentos inter-regionais e rural-urbanos) perderam sua força. Algumas regiões em desenvolvimento podem estar menos urbanizadas, mas em todos os lugares a revolução urbana está em marcha e a urbanização contínua é uma das previsões demográficas mais consensuais. A década atual será testemunha da transição da população mundial a uma população predominantemente urbana. Se a transição de um período marcado por transformações seculares na distribuição populacional para um período de "acomodação" significa mais ou menos migração, o tempo nos dirá. De qualquer maneira, é cada vez mais evidente que uma gama de movimentos diferenciados, os quais têm conseqüências importantes para a sociedade, caracteriza o mundo contemporâneo (Hogan e Cunha, 2001).

A discussão sobre migração e ambiente implica tratar da distribuição dos recursos naturais no território, do uso histórico destes recursos por parte das populações humanas e de seu esgotamento ou degradação.
Também significa tratar das conseqüências de mudanças ambientais provocadas pela mobilidade humana.

Embora este tema estivesse presente na investigação demográfica desde os trabalhos clássicos de Ravenstein (1885) e Everett Lee (1966), que mencionam os recursos naturais nas suas discussões sobre migração, o ambiente físico era tratado geralmente como algo estático, como um recurso a ser explorado ou um obstáculo a ser superado. Enquanto os recursos naturais foram percebidos como ilimitados (uma hipótese incorreta em teoria, mas que é um forte elemento da ideologia desenvolvimentista), era possível ignorar os ciclos ecológicos dinâmicos sem sérias conseqüências para a compreensão das mudanças econômicas e demográficas.

$\mathrm{O}$ que altera a importância do fator ambiental nos estudos de mobilidade populacional é a percepção dos limites dos recursos naturais, representados, antes de tudo, pelo desaparecimento da fronteira. $\mathrm{O}$ esgotamento de solos no Vale do Paraíba e a "marcha" do café para o Oeste Paulista, por exemplo, foram seguidos por outros esgotamentos e outras marchas. Hoje esta resposta demográfica não é mais possível. As fronteiras se foram. E se a concentração da propriedade da terra ainda deixa espaço para o assentamento de grandes contingentes populacionais, isso não muda o fato de que a terra é finita.

Os primeiros estudos demográficos do ambiente refletiam uma visão da relação entre a mobilidade da população e o ambiente que encarava as questões ambientais como mais um fator a ser considerado na explicação da migração. Os problemas relacionados com os recursos naturais eram vistos como tendo chegado a um ponto capaz de interferir nos processos de distribuição populacional. Já não podiam ser considerados como fatores secundários ou estáticos de menor importância.

Logo começam a aparecer estudos de problemas isolados, os quais abriram novas perspectivas de investigação e se multiplicaram em anos recentes. Dentre eles destacam-se: 
- Na Região Metropolitana de São Paulo, os movimentos pendulares diários da população entre o centro e a periferia são um mecanismo para a distribuição de bons empregos: não somente no centro, mas inclusive na periferia (com sua deficiente infraestrutura ambiental), os residentes do centro, que desfrutam de uma melhor qualidade ambiental nos seus bairros de residência, têm os melhores empregos. A migração pendular permite que esse padrão de amenidades ambientais persista (Hogan, 1992).

- No centro petroquímico de Cubatão, uma combinação de deslocamentos diários para trabalhar, seleção migratória, maior rotatividade e segregação residencial indica que a população que sofre as conseqüências da contaminação do ar é um segmento desfavorecido economicamente. A pirâmide social truncada (resultado dos padrões de migração) também significa que Cubatão não tem grupos sociais com uma cultura de organização política suficiente para provocar a ação corretiva por parte do Estado (Hogan, 1993).

- Em alguns contextos latino-americanos, durante os anos 80 , a inversão das tendências de crescimento foi bem recebida como um sinal de esperança de melhoria da qualidade de vida urbana. Mas a queda das taxas de crescimento foi muito desigual em diferentes áreas, algumas das quais cresceram a taxas de 8-9\% anualmente (em particular, as áreas de proteção a mananciais). A poluição de rios locais e de represas não foi corrigida e o racionamento de água persiste em muitas grandes cidades (Marcondes, 1999).

- No "Vale do Aço", em Minas Gerais, uma urbanização periférica fragmentada, provocada pela flexibilização na localização dos fatores de produção, condena os trabalhadores de muitas indústrias a viverem em pedaços de território urbanizados, isolados das indústrias e de outras cidades, com uma infra-estrutura ambiental mínima (Costa, 1995).

- Na Zona Leste de São Paulo e nas favelas de São Paulo e Campinas, a dialética perversa entre condição socioeconômica e distribuição de população reserva as zonas de inundação para os segmentos mais pobres da população (Taschner, 2000; Torres e Cunha; 1994; Torres, 1997).

- O desenvolvimento turístico em regiões pristinas traz consigo a inserção na cultura globalizada à custa da degradação socioambiental (Lopes Junior, 1997). O desenvolvimento turístico acelerado opõe os turistas aos migrantes que mudaram para aquelas regiões em função da demanda de serviços desses turistas, e os dois grupos à população nativa. Todos perdem: os nativos, seu modo de vida tradicional; os migrantes, a tranqüilidade e proximidade da natureza que pensavam ter encontrado; e o ambiente (Luchiari, 1992 e 1997; Ferreira, 1996).

- Populações agrícolas que vivem em unidades de conservação e nos "buffer zones" do entorno movem-se livremente para explorar os recursos naturais, com conseqüências ainda imprevisíveis para a integridade ambiental dessas áreas (Rodrigues, 1995; D’Antona, 1997).

- O crescimento urbano desordenado procede a um ritmo acelerado, até independentemente do crescimento da população. Nas áreas metropolitanas dos Estados Unidos na década de 80 , mesmo as zonas onde a população não cresceu aumentaram sua superficie urbanizada a uma média de 18\% (Pendall, 1999). O "urban sprawl" é também visível em algumas regiões brasileiras, onde igualmente tem conseqüências ambientais importantes (Ojima, 2005). 
A identificação e o estudo de ambientes em situações de risco, ou regiões ecologicamente frágeis (terras semi-áridas ou montanhosas, os trópicos úmidos, entre outras), são uma maneira útil de analisar as conseqüências socioambientais de movimentos populacionais. O turismo, como um tipo de movimento populacional muitas vezes com conseqüências socioambientais devastadoras, merece mais pesquisas. Estudos dessas áreas ecologicamente frágeis mostrarão que "há uma imensa variação geográfica na pressão populacional, o que pode ter pouca relação com a densidade de população" (Zaba e Clarke, 1994, p. 20). Quer dizer, todos os aspectos dos diferentes processos de mobilidade populacional que têm sido examinados e sistematizados ao longo dos anos têm uma dimensão ambiental. São fatores de atração, expulsão e retenção; fatores de mudança e estagnação; segregação residencial; ocupação de novas terras e esgotamento de velhas terras; migração sazonal na agricultura; migração pendular; turismo.

\section{Para uma perspectiva ambiental da mobilidade populacional}

Com o aprofundamento da crise ambiental, a percepção dos limites dos recursos naturais muda a nossa leitura da relação entre sociedade e natureza e transforma a problemática da inter-relação entre mobilidade populacional e ambiente. Agora temos duas perspectivas sobre essa relação e duas ordens de perguntas. A incorporação da dimensão ambiental aos estudos de mobilidade populacional foi somente o primeiro passo de um esforço para responder ao desafio que a questão ambiental representa. Como temos visto, os estudiosos da migração aceitaram esse desafio e deram início a uma bibliografia que está dirigida a vários aspectos dessa questão. Levando a noção de limites à sua conclusão lógica, um novo nível de análise se abre.

Para a presente discussão existem dois limites de interesse: por um lado, os recursos naturais e a resiliência dos sistemas naturais e, por outro, a transição demográfica. Quanto a esse último fator, é claro que no futuro previsível a migração será o componente mais dinâmico da dinâmica demográfica. Embora as taxas de fecundidade total tenham caído de seis para dois filhos, ou até um filho, agora só podem cair, no extremo, a zero. Do mesmo modo, as taxas brutas de mortalidade, baixando de 35 ou 40 para 10 ou 5, agora só podem cair, no extremo, a zero. Esses limites matemáticos, embora não correspondam aos limites sociais e fisiológicos, revelam o estreito espaço para variação no longo prazo. Para a localização da população no espaço, porém, a lógica numérica não é um fator limitante. Para o uso e preservação dos recursos naturais, então, a mobilidade populacional é o fator demográfico mais significativo. Onde a população vive, trabalha e descansa sempre terá um impacto sobre a natureza, e vice-versa.

Terra e água são os maiores exemplos da finitude dos recursos naturais. Mesmo que os avanços tecnológicos possam diminuir a quantidade de terra necessária para a produção de alimentos, não podem aumentar a superficie da Terra. E a água, elemento básico da vida, já mostra sinais de ter alcançado seus limites.

Considerar a volatilidade e imprevisibilidade da mobilidade populacional torna-se, pois, crucial para garantir a sustentabilidade. E os limites ambientais sinalizam a necessidade urgente de conciliar esses limites com a distribução das atividades humanas no espaço. Assim, surge uma nova ordem de perguntas para as ciências populacionais. $\mathrm{O}$ que se exige é uma nova teoria da organzação social do espaço, que comece com a idéia de que os recursos naturais são finitos.

Em muitas regiões, é o recurso água que representa o limite para o crescimento. Soluções tradicionais para responder à demanda incluem obras de engenharia que transportam o precioso líquido de áreas mais bem providas. Em regiões ricas em água como a América do Sul, a questão relevante seria o custo dos projetos de engenharia necessários. Ou não? Desviar a água de uma região para outra encontra, atualmente, resistência política, o que tem frustrado grandes projetos na California, na 
Flórida e no Texas. Em São Paulo, o Sistema Cantareira, que leva $31 \mathrm{~m}^{3} / \mathrm{seg}$ de água de uma bacia vizinha à Região Metropolitana de São Paulo, não contaria, hoje, com as mesmas facilidades encontradas para sua implantação nos anos 70 , quando foi construído. Em todo lugar, é claro que essa solução não é mais viável.

Outras soluções técnicas incluem o uso mais eficiente da água, reduzindo o desperdício e tratando os efluentes urbanos para permitir sua reutilização. Mudanças nos hábitos da população também ajudam a economizar água. As novas agências de bacia, que cobrarão para o uso da água, acelerarão a adoção dessas soluções. O potencial combinado dessas medidas é enorme e sua viabilidade afasta cenários catastróficos. Mas toda a gama de ações propostas somente comprará tempo para a transição a um uso mais sustentável da água.

$O$ que isso significa, para qualquer região específica, é que o tipo de atividade econômica sustentável - e conseqüentemente o tamanho da população - tem limites. As atividades que usam água intensivamente terão de ser removidas para áreas apropriadas, especialmente a agricultura irrigada.

As conseqüências dessa percepção para o padrão de distribuição populacional devem ser consideradas regionalmente. Em primeiro lugar, compreender as relações sociedade-natureza nesse contexto suscita a necessidade de repensar a unidade apropriada de análise. O que se requer é uma unidade territorial onde seja possível observar a dinâmica da natureza e que, ao mesmo tempo, seja relevante para a organização social. Os limites municipais, por exemplo, podem ser adequados para a análise das políticas econômicas e sociais, mas insuficientes para captar os ciclos hidrológicos relevantes de um município determinado. Considerando a importância dos recursos hídricos para as atividades humanas, não surpreende que as bacias tenham surgido como uma unidade de planejamento ambiental.

Quando o recurso estratégico é diferente, outra delimitação territorial será necessária. A preservação da biodiversidade de uma floresta úmida, por exemplo, e os problemas de conflitos entre agricultores, grupos indígenas, turistas, homens de negócio etc. implicam que a delimitação territorial terá de dar conta não só das espécies que são os objetos das políticas de preservação, como também dos ecossistemas onde habitam essas espécies, dos grupos sociais envolvidos e das atividades econômicas que causam impactos sobre esses grupos e essas espécies.

Na prática, a importância dos recursos hídricos está gerando uma nova estrutura administrativa que pode ser adaptada para o estudo e manejo de outros recursos. Mas o ponto, aqui, é que distintos territórios terão diferentes limites dependendo dos recursos em questão. Já que não são sistemas fechados, esses limites não são absolutos. Do ponto de vista da sociedade em seu conjunto, o equilíbrio necessário encontrar-se-á na definição das diferentes vocações ecológicoeconômicas dos diversos territórios dos quais ela é composta. Essas não são vocações puramente naturais, já que o uso da terra no novo milênio é o produto das forças sociais ao longo da história. Considerando que todos os valores não podem ser maximizados no interior de cada unidade territorial, o planejamento econômico-ambiental é a solução inevitável para maximizar os interesses da sociedade. A alternativa é reduzir a qualidade de vida e a qualidade ambiental até seu mínimo denominador comum em todo o território.

Algumas áreas, considerando suas vocações econômico-ecológicas socialmente determinadas, poderão receber mais população e outras, menos. Não podemos, simultaneamente, preservar a biodiversidade e a beleza natural de regiões intactas e reproduzir o mesmo estilo de desenvolvimento que caracteriza as regiões economicamente mais avançadas. A capacidade de absorver contingentes populacionais varia de acordo com os recursos naturais presentes na região, com o acesso a recursos extraterritoriais e com o lugar que a região ocupa em uma divisão territorial do trabalho social. Esse lugar terá de ser negociado na esfera da sociedade no seu conjunto, o que significa uma negociação permanente. 
Esse segundo campo para os estudos da relação entre mobilidade populacional e ambiente continua escassamente ocupado. Pesquisas em andamento em São Paulo (Hogan, 1996; Carmo, 2001; Cunha, 2004) buscam avançar nessa direção. Um estudo do Consejo Nacional de Población de México (Conapo, 1997) focaliza a distribuição populacional, o crescimento econômico e a qualidade ambiental neste país e procura identificar microrregiões cuja base de recursos naturais sustentaria, no longo prazo, as atividades econômicas capazes de criar emprego. O objetivo é identificar aquelas áreas que poderiam reter ou absorver população. Em Maurício, Lutz (1994) desenvolveu um modelo das interrelações entre população, desenvolvimento e ambiente com o objetivo de criar instrumentos de planejamento. Mas ainda há poucos estudos de demografia que analisam a questão da mobilidade populacional no contexto dos limites que o fator ambiental estabelece para o conjunto de ecorregiões da sociedade em geral (ver Hogan, 2001, para um esforço inicial).

Em parte, isso se deve à complexidade da tarefa. Mas também se deve à falta de consenso sobre os limites dos recursos e as conseqüências para a mobilidade. Para as questões específicas mencionadas na primeira parte deste texto, não é necessária uma mudança de paradigma. Para incorporar o fator ambiental à análise de aspectos da mobilidade populacional é requerido apenas que reconheçamos que esse fator já assumiu uma importância considerável na qualidade de vida de populações contemporâneas. Mais difícil é aceitar que o desenvolvimento sustentável esteja baseado em limites ambientais e disso tirar as conclusões lógicas acerca do uso da terra. Essa perspectiva orienta muitos ambientalistas mas ainda poucos demógrafos.

\section{Padrões e processos de distribuição populacional e a vulnerabilidade de migrantes: $A \rightarrow P$}

A migração também pode ser uma conseqüência de mudança ambiental. Izazola e Marquette (1995) estudaram mulheres de classe média cujas famílias abandonaram a Cidade de México para viverem em cidades menores do interior, em busca de uma melhor qualidade de vida. Ou seja, a poluição do ar na capital foi um fator importante na decisão de migrar. A dimensão desse fenômeno em outros países é desconhecida, embora, seguramente, a qualidade ambiental figure entre os motivos daqueles que trocam as grandes cidades por uma vida mais tranqüila em lugares menores. Parte desse movimento migratório implica um movimento diário até o lugar de trabalho, algumas vezes de grande número de trabalhadores (Hogan, 1993). A erosão e desgaste de solos também provocam a migração rural-urbana, um processo pouco estudado desta perspectiva.

Uma primeira abordagem para captar esta dimensão das relações populaçãoambiente foi o conceito de populações em situação de risco. Considerando que as conseqüências da deterioração ambiental não são percebidas de maneira igual por distintos grupos sociais, nem são sentidas de maneira uniforme ao longo de todo o território, as categorias usuais na análise demográfica nem sempre são capazes de revelar essas conseqüências. A localização de muitas favelas, por exemplo, as expõe a inundações sazonais (e a um aumento na incidência de doenças tais como a leptospirose) e a deslizamentos provocados por chuvas fortes. Desastres considerados como naturais têm sido estudados por muito tempo sob diversas perspectivas e oferecem importantes elementos para a análise da vulnerabilidade de populações específicas. Blaikie et al. (1994), por exemplo, investigam as maneiras pelas quais populações ganham acesso a recursos nessas situações de risco.

Torres (1999) examinou as situações ecológicas de bairros afetados por inundações e as características sociodemográficas dos seus residentes, tendo concluído que "a noção de risco muda de grupo social a grupo social, como também com o tempo". Para ele, a tarefa do analista é buscar conexões entre risco e condição socioeconômica, no sentido de entender uma 
dinâmica socioambiental complexa. A idéia de risco implica a existência de um agente ameaçador e de um agente receptor.

A busca de conceitos para elaborar um novo paradigma terá de ir além da análise demográfica tradicional. As interfaces da demografia com outras ciências ajudarão a entender o novo lugar de fatores populacionais naquilo que E.O. Wilson chamou de o "environmental century". Mesmo a sustentabilidade, como a meta maior, ainda é um conceito abstrato que serve mais para orientar a nossa visão do futuro do que para elaborar hipóteses de pesquisa. Mas o senso comum e a exploração intuitiva, na história da ciência, eventualmente dão lugar a conceitos mais sistematizados e mais cuidadosamente definidos. No mesmo universo teórico da sustentabilidade onde também encontramos termos ainda imprecisos como qualidade de vida e qualidade ambiental, risco, hazard (perigo), vulnerabilidade são conceitos que abordam a questão do outro (negativo) lado da moeda. Esse último termo encontra-se em várias disciplinas no campo ambiental e, embora ainda falte um consenso conceitual, capta dimensões que ainda não foram delimitadas com clareza (Marandola Junior e Hogan, 2004a, 2004b e 2004c; Hogan e Marandola Junior, 2005).

Ao se traçar o vínculo entre mobilidade populacional e ambiente, a flecha causal geralmente tem ido de população a ambiente $(P \rightarrow A)$. Os efeitos da concentração de população sobre a integridade ecológica do território e a necessidade de equilibrar com cuidado a distribuição territorial à base de recursos começam a ser incorporados à análise demográfica, como vimos acima. Mas a relação $A \rightarrow P$ é de importância igual ou até maior. $O$ conceito de vulnerabilidade é útil para destrincharmos essa relação. A vulnerabilidade nos ajuda a diferenciar o impacto do risco do perigo objetivo em si mesmo.

Nesta como em outras áreas de análise ambiental, um dos primeiros desafios dos estudiosos é o desenvolvimento de conceitos apropriados. Agregar significados mais densos a conceitos tomados do discurso não-científico, conectá-los a marcos teóricos mais amplos, é inevitável. Vulnerabilidade e risco são conceitos desse tipo. Foram escolhidos por estudiosos de questões ambientais porque têm uma ressonância que o nosso vocabulário tradicional não possui. Permitem-nos, em particular, associar características dos mundos natural e social, um requisito imposto pelas realidades ambientais. É necessário ir além do sentido comum na construção de uma sociologia ambiental ou uma demografia ambiental.

Existem pelo menos dois aspectos da vulnerabilidade que são relevantes aqui: vulnerabilidade de lugar e vulnerabilidade de grupos sociais. A primeira é mais apropriada para a discussão anterior e a segunda é especialmente útil para desemaranhar as relações entre os impactos sociais e ecológicos da mudança ambiental sobre pessoas. Os geógrafos seguiram as duas direções, e até agora não há consenso conceitual nesse campo. A cara da moeda que nos interessa nesta seção é a vulnerabilidade dos indivíduos ou grupos diante dos fatores ambientais. Sabemos que a mudança ambiental (escassez ou degradação de recursos) afeta diferentes grupos de maneira diferente. Impactos ambientais não são democráticos, igualmente compartilhados por todos.

As lógicas do industrialismo e do consumismo produzem, simultaneamente, estresse ambiental e padrões socioespaciais que localizam a vulnerabilidade em grupos sociais específicos. Ao examinarmos a dimensão espacial dos processos socioeconômicos e demográficos, percebemos que a distribuição desigual dos serviços urbanos é um componente importante da vulnerabilidade socioambiental. A segregação espacial, o crescimento das favelas e a exclusão social são diferentes aspectos da falta de acesso a estilos de vida modernos. A falta de acesso a bens de consumo é acompanhada pela falta de acesso aos serviços públicos, situação agravada pelas condições de vida destas populações vulneráveis. A compreensão da vulnerabilidade como um processo que envolve tanto a dinâmica social como as condições ambientais será 
aprofundada em estudos de caráter local, em lugares específicos.

Muito do trabalho analítico sobre o desenvolvimento centrado na análise de vulnerabilidade e risco foi levado a cabo em contextos nos quais a escassez de alimentos é o problema central. Especialmente na África, a vulnerabilidade das populações rurais às secas e à perda de colheitas motivou esforços para afinar os conceitos necessários à análise, previsão, prevenção e mitigação desses eventos. Em outras regiões, outros fatores serão mais importantes. O caráter urbano da América Latina, por exemplo, leva-nos a examinar o impacto sobre o bem-estar de problemas tais como o acesso limitado à água tratada, ao tratamento de esgotos, à coleta e disposição adequada de resíduos domésticos e à pavimentação de ruas; a suscetibilidade a inundações e deslizamentos e a poluição do ar. Esses fatores representam ameaças à vida e, também, a exposição a uma ampla gama de enfermidades disseminadas pelo ar e pela água.

A falta de consenso sobre definições apropriadas tem levado muitos pesquisadores, como Liverman (1990), a ampliar seu enfoque: ser vulnerável à seca significa carecer de defesas ambientais, tecnológicas, econômicas ou políticas contra esses impactos. Cutter (1996), em sua revisão do conceito, identifica 18 definições diferentes, agrupando estas definições em três categorias: vulnerabilidade como uma condição preexistente; como uma resposta moderada e como um risco de lugar. Essa última definição incorpora características sociodemográficas e econômicas da população como aspectos intrínsecos de vulnerabilidade. A vulnerabilidade está "geograficamente centrada" mas com efeitos diferentes de acordo com a capacidade de autoproteção da população.

Neste artigo, trata-se o risco da forma tradicional na demografia e na epidemiologia, em termos probabilísticos (um risco de $20 \%$ de ser afetado por um perigo específico); perigo é o fato físico, concreto (inundação, contaminação, seca) e vulnerabilidade incorpora condições sociais e econômicas que predispõem certos indivíduos ou grupos a uma maior ou menor suscetibilidade ao perigo (ver os mencionados textos de Marandola Junior e Hogan para uma revisão sistemática desses conceitos). Isso é diferente do debate atual travado na literatura da sociologia ambiental sobre sociedade de risco, que considera outras dimensões relacionadas à compreensão das mudanças sociais ao nível macro na época "industrial tardia" ou "pós-industrial" (ver, por exemplo, Giddens, 1991; Beck, 1992). Aqui nosso interesse é mais modesto: caracterizar suscetibilidades às condições negativas do ambiente por parte dos indivíduos, grupos ou categorias sociodemográficas, de acordo com suas diferentes situações sociais, econômicas, políticas e culturais. Para este propósito, trabalhos recentes realizados por geógrafos e pesquisadores da saúde (especialmente sobre HIV-Aids), dirigidos à identificação das condições mediadoras entre um perigo objetivo e suas conseqüências, são um ponto de partida útil.

Mas o que isso tem a ver com a mobilidade populacional? A migração em si é um fator que aumenta a vulnerabilidade? Certamente. A falta de conhecimento do novo lugar e as fracas ou inexistentes redes sociais se combinam com a pobreza e baixos níveis de escolaridade para colocar maiores cargas ambientais sobre os migrantes. A pobreza de um migrante é agravada por sua falta de conhecimento, que o expõe à água poluída, a sistemas primitivos de disposição de esgoto e de resíduos sólidos e a uma tendência a buscar residência em zonas propensas a inundações ou deslizamentos. Esses migrantes pagam um preço muito mais alto que outros - talvez igualmente pobres, mas com mais tempo de residência na área. As redes sociais de antigos residentes urbanos são mais complexas e os protegem melhor (reduzem sua vulnerabilidade a) desses perigos ambientais. A falta de habitação de baixo custo afeta mais diretamente os novos migrantes, já que os bairros pobres tradicionais não podem acomodar os recémchegados, que vão buscar um lugar nas periferias urbanas, onde há uma infra-estrutura ainda mais precária. Isto é igualmente 
verdadeiro para os migrantes rurais que se dirigem às fronteiras agrícolas. A grande incidência de malária no país ocorre em áreas recentemente abertas, onde os novos migrantes estão expostos a riscos intensificados por sua ignorância sobre algumas medidas simples de proteção. A inexperiência com diferentes tipos de solos e climas leva à degradação dos ambientes locais e ao fracasso de agricultores familiares que não conseguem se estabelecer na região.

Quais são os fatores que poderiam mitigar a vulnerabilidade de novos migrantes? A vulnerabilidade promove a migração? A migração diminui a vulnerabilidade daqueles que ficam?

\section{Considerações finais}

Esse intenso processo de periferização experimentado pelas cidades latinoamericanas provocou sérias conseqüências ambientais e sociais como a degradação dos recursos naturais e da qualidade do ambiente; descontinuidades na rede de infra-estrutura urbana; o agravamento dos problemas sociais na periferia; o comprometimento das finanças públicas com os crescentes custos da urbanização; o estabelecimento de espaços segregados dirigidos exclusivamente à população de baixa renda, entre outros. Estas populações são aquelas com menores recursos para se protegerem dos riscos ambientais.

O que pode ser feito? Não há nenhuma tábula rasa. Nosso ponto de partida somente pode ser o ambiente natural e construído de hoje. O planejamento da distribuição espacial não pode ser pensado como um equilíbrio racional de população às qualidades naturais de ecossistemas locais, ignorando séculos de história econômica e demográfica. O ponto é: o que podemos fazer, na situação atual, para minimizar a degradação ambiental e maximizar a qualidade de vida? As soluções incluem:

- Zoneamento aos níveis meso (bacias) e micro (cada cidade). Como unidade de planejamento, a bacia está se tornando uma alternativa viável diante das decisões fragmentadas e isoladas de cada cidade. Se não houver empenho em definir o uso da terra em todos os níveis, o futuro será uma extensão das alarmantes tendências atuais.

- Acabar com os incentivos fiscais como ferramenta de municípios para atrair investimentos, responsáveis por provocar a competição desordenada, caótica, que não respeita as considerações ambientais.

- Universalização de serviços urbanos como o acesso a água tratada e a coleta e tratamento de esgoto.

- Administração integrada do transporte, o que não se deve limitar à construção de novas rodovias, que somente reforçarão as tendências atuais.

- Administração integrada dos recursos hídricos.

Essas soluções dependem de dois problemas relacionados de distribuição. Uma maior densidade em centros já estabelecidos, junto com o zoneamento, pode interromper o urban sprawl e facilitar a construção de infra-estrutura sanitária para todos os segmentos da população.

São sinais de mudança os novos arranjos institucionais que podem afetar o uso da terra, como as agências e comitês de bacia, secretarias e conselhos municipais e estaduais de meio ambiente. As condições existem para um planejamento mais integrado do transporte e do desenvolvimento regional, o que poderia dirigir a espacialização da concentração populacional. Não há, porém, nenhum sinal concreto de que essas instituições estejam a ponto de propor medidas efetivas para o ordenamento do uso da terra. As opiniões das elites e do público em geral não mostram a saliência desses problemas. A existência de indicações positivas e negativas para a implementação de um planejamento efetivo do uso do solo faz do resultado uma incerteza.

Neste início do século XXI o mundo encontra-se no limiar de uma era de póstransição demográfica. Com as taxas de 
fecundidade convergindo para um nível de reposição, o crescimento populacional em muitos países em desenvolvimento terminará em um futuro próximo. De fato, não há nenhuma razão para esperar que o declínio de fecundidade vá segurar-se ao nível de reposição, como não o fez na Europa; os mesmos fatores indicados para explicar a baixa fecundidade nesse continente têm sido apontados para explicar as tendências atuais na América Latina.

Este é claramente o futuro que os demógrafos previram quando se formulou a teoria da transição demográfica, em meados do século XX. Embora o caminho da transição tenha sido diferente nos distintos países, e continuará sendo diferente, as considerações de longo prazo sobre o desenvolvimento sustentável deverão dar conta de uma população em torno de dez bilhões de pessoas. A sustentabilidade demográfica nessa nova situação adquire um novo significado.

E não serão o tamanho da população ou as taxas de crescimento que ocuparão o centro da atenção. $\mathrm{O}$ manejo prudente da sustentabilidade implica, para a dinâmica demográfica, um ajuste cuidadoso da distribuição da população à base de recursos

\section{Referências bibliográficas}

BECK, U. Risk society: toward a new modernity. Londres: Sage Publications, 1992.

BILSBORROW, R.E. Population pressures and agricultural development in developing countries: a conceptual framework and recent evidence. World Development, vol. 15, n. 2, p. 183-203, 1987.

Migration, population change and the rural environment. In: Population, environmental change and security. Washington: The Woodrow Wilson International Center for Scholars, Environmental Change and Security Project, Working Paper Series, n. 2, 2001.

BILSBORROW, R.E. e HOGAN, D.J. (Eds.). Population and deforestation in the humid tropics. Liége: IUSSP, 1999. naturais de um determinado território. Esse ajuste não será feito com considerações técnicas sobre os recursos, senão com a definição social do papel de cada unidade do mosaico de ecossistemas da sociedade. Todos os fatores que contribuem para uma compreensão da dinâmica da mobilidade populacional devem receber mais atenção para alcançarmos esse ajuste da distribuição da população.

O campo de estudos de população e ambiente tornou-se consideravelmente mais complexo na década de 90. Para os demógrafos, os desafios são vários: refinar os conceitos "guarda-chuva", tais como qualidade ambiental, qualidade de vida, sustentabilidade e vulnerabilidade; repensar as unidades de análise para captar a dinâmica ecológica; incorporar novos recursos técnicos para abordar aspectos globais e redimensionar a extensão do fenômeno ecológico. Os estudiosos de população compartilham muitos desses desafios com outros especialistas. Em alguns aspectos, têm uma vantagem - 0 tratamento de escalas temporais, por exemplo. A julgar pela crescente bibliografia neste campo, os demógrafos aceitaram estes desafios.

BIRDSALL, N., KELLEY, A.C. e SINDING, S.W. (Eds.). Population matters: demographic change, economic growth, and poverty in the developing world. Nova York: Oxford University Press, 2001.

BLAIKIE, P., CANNON, T., DAVIS, I. e WISNER, B. At risk: natural hazards, people's vulnerability and disasters. Londres: Routledge, 1994.

CARMO, R.L. A água é o limite? Redistribuição espacial da população e os recursos hídricos no Estado de São Paulo. Tese de doutorado em Demografia. Campinas: Universidade Estadual de Campinas, 2001.

CONAPO - CONSEJO NACIONAL DE POBLACIÓN. Condiciones ambientales de microregiones estratégicas para 
modificar la distribución espacial de la población en México. La microregión Obregón. México, DF: Conapo, 1997.

COSTA, H.S.M. Vale do aço: da produção da cidade moderna sob a grande indústria à diversificação do meio ambiente urbano. Tese de doutorado em Demografia. Belo Horizonte: Universidade Federal de Minas Gerais, 1995.

CLARKE, J.I. e NOIN, D. (Eds.). Population and environment in arid regions. Paris: Unesco, 1998.

CLARKE, J.I. e TABAH, L. (Eds.). Populationenvironment-development interactions. Paris: Cicred, 1995.

CUNHA, J.M.P. Urbanización, redistribuición espacial de la población y transformaciones socioeconomicas en América Latina. Serie Población y Desarrollo, Cepal, Santiago de Chile, vol. 30, 2002, p. 3-52.

Um sentido para a vulnerabilidade sociodemográfica nas metrópoles paulistas. Revista Brasileira de Estudos de População, vol. 21, n. 2, jul./dez., p. 343347, 2004.

CUNHA, J.M.P., CARMO, R.L., HOGAN, D.J. e JAKOB, A.A. Social vulnerability in the metropolitan context: the case of Campinas. Trabalho apresentado à 2005 Annual Meeting of the Population Association of America. Philadelphia, 2005.

CUTTER, S.L. Vulnerability to environmental hazards. Progress in Human Geography, vol. 20, n. 4, p. 529-539, 1996.

D'ANTONA, A.O. O verão, o inverno e o inverso: sobre o modo de vida de comunidades residentes na região do Parque Nacional dos Lençóis Maranhenses. Dissertação de mestrado. Campinas: Universidade Estadual de Campinas, 1997.

EZCURRA, E., MAZARI-HIRIART, M., PISANTY, I. e AGUILAR, A.G. The basin of Mexico: critical environmental issues and sustainability. Tóquio: United Nations University Press, 1999.

EUROPEAN JOURNAL OF POPULATION. Special issue on population and environment, n. 8, 1992.
FERREIRA, L. A floresta intransitiva: conflitos e negociações na Mata Atlântica, SP. Tese de doutorado em Ciências Sociais. Campinas: Universidade Estadual de Campinas, 1996.

GIDDENS, A. Modernity and self-identity: self and society in the later modern age. Stanford: Stanford University Press, 1991.

HINRICHSEN, D. e ROBEY, B. Population and the environment: the global challenge. Population Reports, Johns Hopkins University, School of Public Health, Series $\mathrm{M}, 15$. Population Information Program, 2000.

HOGAN, D.J. The impact of population growth on the physical environment. European Journal of Population, n. 8, p. 109-123, 1992.

Population growth and distribution: their relations to development and the environment. Santiago de Chile: United Nations, Celade, Background Paper DDR/ 5, 1993.

Population and environment in Brazil: a changing agenda. In: CLARKE, J.I. e TABAH, L. (Eds.), Populationenvironment-development interactions. Paris: Cicred, 1995a, p. 245-252.

Population, poverty and pollution in Cubatão, São Paulo. Geographia Polonica, Warsaw, Polish Academy of Sciences, n. 64 (editado por POTRIKOWSKA, A. e CLARKE, J.I.), p. 201-224, 1995b.

Desenvolvimento sustentável na bacia hidrográfica do rio Piracicaba: limites e possibilidades. In: FERREIRA, L.C. e VIOLA, E. (Eds.), Incertezas da sustentabilidade na globalização. Campinas: Editora da Unicamp, 1996, p. 161-176.

Mobilidade populacional e meio ambiente. Revista Brasileira de Estudos de População, vol. 15, n. 2, 1998.

. La relación entre población y medio ambiente. Retos y desafíos para la demografía. In: IZAZOLA, H. (Ed.), Población y medio ambiente: descifrando el rompecabezas. Zinacantepec: El Colégio Mexiquense/Somede, 1999, p. 27-57. 
Hogan, D.J. Demographic dynamics and environmental change in Brazil. Ambiente e Sociedade, vol. 4, n. 9, p. 43-73, 2001.

HOGAN, D.J., CARMO, R.L., ALVES, H.P.F. e RODRIGUES, I.A. Urbanization, migration and sustainability in the Ribeira Valley: environmental conservation and living conditions of local populations in Brazil's Atlantic Forest. In: HOGAN, D.J. (Org.), Population change in Brazil: contemporary perspectives. Campinas: Nepo/Unicamp, 2001, p. 287-307.

HOGAN, D.J., CUNHA, J.M.P. e CARMO, R.L. Land use and land cover change in Brazil's Center-West: demographic, social and environmental consequences. In: HOGAN, D.J. (Org.), Population change in Brazil: contemporary perspectives. Campinas: Nepo/Unicamp, 2001, p. 309-330.

HOGAN, D.J. e CUNHA, J.M.P. Internal migration in developing countries. In: SMELSER, N.J. e BALTES, P.B. (Eds.), International encyclopedia of the social and behavioral sciences. Amsterdam: Elsivier, 2001.

HOGAN, D.J. e MARANDOLA JR., E. Towards an interdisciplinary perspective on vulnerability. In: Population, space and place, 2005, no prelo.

IZAZOLA, H. Población y meio ambiente: descifrando el rompecabezas. Zinacantepec: El Colegio Mexiquense/Somede, 1999.

IZAZOLA, H. e LERNER, S. (Eds.). Población y ambiente: nuevas interrogantes a viejos problemas? México: Somede, 1993.

IZAZOLA, H e MARQUETTE, C. Migration in response to the urban environment: outmigration by middle-class women and their families from Mexico City after 1985. Geographia Polonica, Warsaw, Polish Academy of Sciences, n. 64 (editado por POTRIKOWSKA, A. e CLARKE, J.I.), p. 225256, 1995.

LEE, E. A theory on migration. Demography, vol. 3, n. 1, p. 47-57, 1966.

LIVERMAN, D. Vulnerability to drought in Mexico: the case of Sonora and Puebla in
1970. Annals of the Association of American Geographers, n. 80, 1990, p. 49-72.

LOPES JUNIOR, E. A construção social da cidade do prazer: urbanização turística, cultura e meio ambiente em Natal (RN). Tese de doutorado em Ciências Sociais. Campinas: Universidade Estadual de Campinas, 1997.

LUCHIARI, M.T.D.P. Caiçaras, migrantes e turistas: a trajetória da apropriação da natureza no litoral norte paulista (São Sebastião - Distrito de Maresias). Tese de mestrado em Sociologia. Campinas: Universidade Estadual de Campinas, 1992.

Ubatuba: expressões e impressões da população sobre o espaço. Tese de doutorado em Ciências Sociais. Campinas: Universidade Estadual de Campinas, 1997.

LUTZ, W. (Ed.). Population-developmentenvironment: understanding their interactions in Mauritius. Berlim: SpringerVerlag, 1994.

LUTZ, W., PRIETO, L. e SANDERSON, W. (Eds.). Population, development and environment on the Yucatán peninsula: from ancient Maya to 2030. Laxenberg: IIASA, 2000.

MARANDOLA JR., E. e HOGAN, D.J. O risco em perspectiva: tendências e abordagens. Geosul, n. 38, p. 25-58, 2004a.

. Natural hazards: o estudo geográfico dos riscos e perigos. Ambiente e Sociedade, v. 7, n. 2, p. 95-109, 2004b.

. Vulnerabilidades e riscos: entre geografia e demografia. Revista Brasileira de Estudos de População, no prelo, 2004c.

MARCONDES, M.J.A. Cidade e natureza. São Paulo: Studio Nobel, 1999.

MARTINE, G. (Ed.). População, meio ambiente e desenvolvimento: verdades e contradições. Campinas: Editora da Unicamp, 1993.

NACIONES UNIDAS. Panorama social de América Latina. Santiago do Chile: Cepal, 2001. 
OJIMA, R. Urban sprawl e riscos ambientais na Região Metropolitana de Campinas. Projeto de doutorado em Demografia. Unicamp, 2005.

PENDALL, R. Do land-use controls cause sprawl? Environment and Planning B: Planning and Design, n. 26, 1999.

PEZZOLI, K. Human settlements and planning for ecological sustainability: the case of Mexico City. Cambridge: MIT Press, 1998.

POTRYKOWSKA, A. e CLARKE, J.I. (Eds.). Population and environment in industrialized regions. Special issue of Geographia Polonica, Warsaw, Polish Academy of Sciences, n. 64, 1995.

PROVENCIO, E. e CARABIAS, J. La gente y su medio en cuatro zonas ecológicas del campo mexicano. In: IZAZOLA, H. e LERNER, S. (Eds.), Población y ambiente: nuevas interrogantes a viejos problemas? México: Somede, 1993, p. 145-166.

RAVENSTEIN, E.G. The laws of migration. Journal of the Statistical Society, n. 47, p. 167-227, 1885.

RODRIGUES, I.A. Áreas naturais sob proteção: estabelecimento e avanços nas medidas de conservação ambiental um estudo no Vale do Ribeira, São Paulo. Tese de mestrado em Sociologia. Campinas: Universidade Estadual de Campinas, 1995.
RUNNELS, C.N. Environmental degradation in Ancient Greece. Scientific American, March, p. 72-75, 1995.

SAWYER, D.R. Deforestation and malaria in Rondônia. In: BILSBORROW, R.E. e HOGAN, D.J. (Eds.), Population and deforestation in the humid tropics. Liége: IUSSP, 1999.

TASCHNER, S.P. Degradação ambiental em favelas de São Paulo. In: TORRES, H.G. e COSTA, H. (Eds.), População e meio ambiente: debates e desafios. São Paulo: Senac, 2000, p. 271-297.

TORRES, H.G. Desigualdade ambiental na cidade de São Paulo. Tese de doutorado em Ciências Sociais. Campinas: Universidade Estadual de Campinas, 1997.

A demografia do risco ambiental. In: TORRES, H.G. e COSTA, H. (Eds.), População e meio ambiente: debates e desafios. São Paulo: Senac, 2000.

TORRES, H.G. e COSTA, H. (Eds.). População e meio ambiente: debates e desafios. São Paulo: Senac, 2000.

TORRES, H. e CUNHA, J.M.P. População sujeita a riscos de inundação: o caso de Campinas. ENCONTRO NACIONAL DE ESTUDOS POPULACIONAIS, 9, Belo Horizonte, 1994. Anais... Abep, 1994.

ZABA, B. e CLARKE, J.I. Environment and population change. Liège: Ordina Editions, 1994.

\section{Abstract \\ Population mobility, environmental sustainability and social vulnerability}

This article reviews research on population and environment, with particular emphasis on the Brazilian case. Attention is focused on the relations between patterns of population mobility and environmental change. With mortality and fertility rates already having experienced major transitions and now experiencing slower change, migration becomes the central factor in population change and its impacts on the environment. In the long term, this is the variable which will always inspire concern. Although the major internal migration in the second half of the 20th century (rural-urban and inter-regional) has slowed considerably, intra-regional moves continue to be important. Other mobility processes, 
especially commuting and tourism, also affect the integrity of natural resources and must be continually evaluated. Ecological-economic zoning, and its impacts on population movements, will be a basic requirement of the 21 st century.

Key words: Population mobility. Migration. Environment. Urbanization. Ecological-economic zoning.

Recebido para publicação em 10/05/2005.

Aceito para publicação em 24/06/2005. 